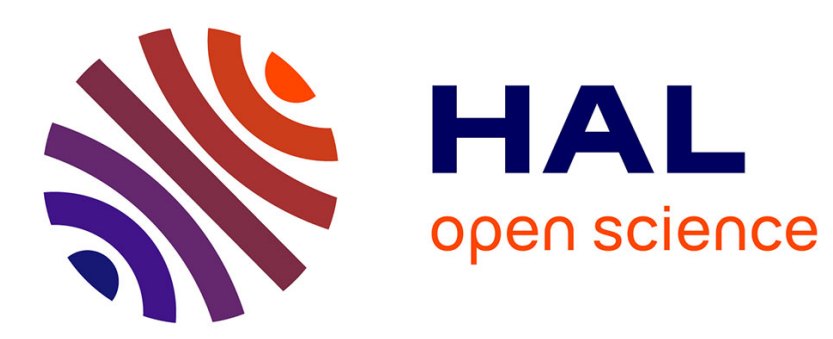

\title{
COLOUR CENTRES IN NON-ALKALI HALIDES.F CENTERS IN IONIC CRYSTALS : ANALYSIS BY ABSORPTION SPECTRUM MOMENTS
}

\author{
M. Brauwers
}

\section{- To cite this version:}

M. Brauwers. COLOUR CENTRES IN NON-ALKALI HALIDES.F CENTERS IN IONIC CRYSTALS : ANALYSIS BY ABSORPTION SPECTRUM MOMENTS. Journal de Physique Colloques, 1976, 37 (C7), pp.C7-181-C7-182. 10.1051/jphyscol:1976741 . jpa-00216898

\section{HAL Id: jpa-00216898 https://hal.science/jpa-00216898}

Submitted on 1 Jan 1976

HAL is a multi-disciplinary open access archive for the deposit and dissemination of scientific research documents, whether they are published or not. The documents may come from teaching and research institutions in France or abroad, or from public or private research centers.
L'archive ouverte pluridisciplinaire HAL, est destinée au dépôt et à la diffusion de documents scientifiques de niveau recherche, publiés ou non, émanant des établissements d'enseignement et de recherche français ou étrangers, des laboratoires publics ou privés. 


\title{
F CENTERS IN IONIC CRYSTALS : ANALYSIS BY ABSORPTION SPECTRUM MOMENTS (*)
}

\author{
M. BRAUWERS (**) \\ Department of Theoretical Physics, University of Liège at Sart Tilman, \\ B-4000 Liège I, Belgium
}

\begin{abstract}
Résumé. - L'analyse par les moments du spectre d'absorption fournit, pour l'état fondamental du centre, le rayon moyen, l'énergie cinétique moyenne et la charge moyenne vue par l'électron. Cette méthode peut être appliquée aux cas des halogénures alcalins et halogénures d'argent ; elle fournit également des indications sur la distribution de charge dans l'état fondamental du centre.

Abstract. - Analysis by absorption spectrum moments gives the ground state mean radius, mean kinetic energy and mean charge density seen by the electron. This method can be applied to the cases of alkali and silver halides and provides information on the ground state charge distribution in the center.
\end{abstract}

The moments of the absorption coefficient are numerically computed from the experimental absorption band and are compared with their theoretical expressions. This allows us to determine characteristic parameters of the F-center ground state : mean radius, mean kinetic energy and mean charge density seen by the electron.

This procedure can be used to study the ground state of the F center in alkali halides [1] and of a shallow center in silver halides [2]. In this last case, one has to assume that the experimental absorption bands [3] are due to absorption by electrons bound in an electrostatic potential.

Let us recall the basic assumptions we need in our analysis by absorption spectrum moments.

(*) Supported by ESIS programme, University of Antwerp UIA and University of Liège.

(**) Aspirant FNRS, Belgium.
The ratio of the $1 \mathrm{~s}-2 \mathrm{p}$ transition energy to the LO phonon energy is about $\mathbf{1 0 0}$ for alkali halides and a little more than 1 for silver halides. Therefore, an adiabatic approximation is certainly valid for the alkali halides but is questionable for the silver halides although it has been used with success to calculate the relative intensities of the peaks in the phonon sideband [4].

The radius of the electron orbit is of the order of magnitude of the interionic distance $d$ in the alkali halides and far larger than $d$ in the silver halides. As a consequence, the lattice can be treated as a continuous polarizable medium and the band mass approximation is appropriate in the silver halides; these two last assumptions are more questionable in the alkali halides.

The moments have been numerically computed from the experimental absorption bands in $\mathrm{KBr}$ [5],

\section{TABLE I}

Results obtained from the computation of the moments for the mean-square radius $\left\langle r^{2}\right\rangle^{1 / 2}$, the mean kinetic energy $<p^{2} / 2 m>$ and the mean charge density $<\rho>$ seen by the electron. The band mass is used except for the values given in parenthesis which are obtained by replacing the band mass with the free-electron mass. Fourth line : interionic distance d [8].

$\begin{array}{ccccc} & \mathrm{KBr} & \mathrm{KCl} & \mathrm{RbCl} & \mathrm{AgBr} \\ \left\langle r^{2}\right\rangle^{1 / 2}(\AA) & 3.88(2.36) & 3.36(2.22) & 3.56(2.34) & 38(17.6) \\ \left\langle\frac{p^{2}}{2 m}\right\rangle(\mathrm{eV}) & 1.54 & 1.74 & 1.56 & 0.036 \\ \frac{\langle\rho\rangle}{|e|}\left(\AA^{-3}\right) & 0.0082(0.0223) & 0.0114(0.0262) & 0.0090(0.0209) & 0.102(0.477) \times 10^{-4} \\ d(\AA) & 3.29 & 3.14 & 3.27 & 2.88\end{array}$


$\mathrm{KCl}$ and $\mathrm{RbCl}$ [6], $\mathrm{AgBr}$ [3]. The detailed theoretical expressions of the moments have been given previously [1] and the results obtained for the mean radius, the mean kinetic energy and the mean charge density seen by the electron are reported in table I.

These results can be used to determine the ground state charge distribution in the center. It is not possible, with these three pieces of information, to obtain the detailed structure of the charge distribution related to the discrete structure of the lattice, but rather the envelope of this charge distribution. As the charge distribution probably falls off exponentially at large distances, it can be expanded in Laguerre functions. If this expansion is restricted to the two first terms, we get for the ground state charge distribution

$$
\rho_{\mathrm{e}}(\mathbf{r})=e A(1+a r) \mathrm{e}^{-\chi r}(a, \chi>0)
$$

where $e$ is the electron charge and $A$ is a normalization constant. The two parameters $a$ and $\chi$ are determined using the values obtained for the mean radius and the mean charge density seen by the electron, whereas the value obtained for the mean kinetic energy can be used to check the model consistency. The results obtained for $a, \chi$ and $A$ are reported in table II, together with the mean kinetic energy computed with a wave function derived from (1) and with the set of values obtained for $a, \chi$ and $A$. In the alkali halides, the check on the mean kinetic energy does not allow us to decide if the electron mass in the center is the band mass or the free-electron mass whereas, in $\mathrm{AgBr}$, we have certainly to use the band mass (this result is in agreement with the large electron orbit). However, in $\mathrm{KCl}$, a comparison with ENDOR experimental data [7] showed that a good agreement is obtained when the band mass is used in the theory [1]. On the other hand, the agreement obtained on the mean kinetic energy for $\mathrm{AgBr}$ indicates that the adiabatic approximation is probably valid for the ground state of the shallow center in this compound. Let us remark that the ratio $a / \chi$ is about 1 in the alkali halides and about 0.5 in $\mathrm{AgBr}$, when the band mass is used in the theory. As a consequence, the shallow center in $\mathrm{AgBr}$ is closer to a hydrogenlike system than the $F$ center in alkali halides. This gives an estimate of the shallow center ionization energy which is equal (with opposite sign) to the mean kinetic energy.

\section{TABLE II}

Values obtained for the parameters $a, \chi$ and $A$ defined in the charge distribution (1); mean kinetic energy computed with these sets of parameters. The band mass is used except for the values given in paranthesis which are obtained by replacing the band mass with the free-electron mass.

$\begin{array}{ccccc} & \mathrm{KBr} & \mathrm{KCl} & \mathrm{RbCl} & \mathrm{AgBr} \\ a\left(\AA^{-1}\right) & - & - & - & - \\ \chi\left(\AA^{-1}\right) & 1.095(4.32) & 1.41(4.52) & 1.44(4.64) & 0.060(0.616) \\ A\left(\AA^{-3}\right) & 1.093(1.85) & 1.27(1.96) & 1.20(1.86) & 0.108(0.248) \\ \left\langle\frac{p^{2}}{2 m}\right\rangle(\mathrm{eV}) & 0.013(0.0314) & 0.0186(0.0383) & 0.0149(0.0304) & 0.191(0.717) \times 10^{-4} \\ & 1.77(1.72) & 1.99(1.94) & 1.78(1.73) & 0.033(0.110)\end{array}$

References

[1] Brauwers, M., Evrard, R. and Kartheuser, E., Phys. Rev. B 12 (1975) 5864.

[2] Brauwers, M., Evrard, R. and Kartheuser, E., Solid State Commun. 19 (1976) 857.

[3] Brandt, R. C. and Brown, F. C., Phys. Rev. 181 (1969) 1241.

[4] Devreese, J., Evrard, R. and Kartheuser, E. in Optical Properties of Solids, edited by E. D. Haidemenakis (Gordon and Breach) 1970, 383 ;
Devreese, J., Evrard, R. and Kartheuser, E., Solid State Commun. 7 (1969) 767.

[5] Dutton, D. and Maurer, R., Phys. Rev. 90 (1953) 126. [6] LÜTY, F., Z. Phys. 160 (1960) 1.

[7] Kersten, R., Phys. Status Solidi 29 (1968) 575.

[8] SeItZ, F., The Modern Theory of Solids (McGraw-Hill, New York) 1940.

\section{DISCUSSION}

C. L. Marquardt. - I believe that the work of Brandt and Brown concluded that their absorption band could not be ascribed to an $F$ center. Does your work have any implications for reinterpretation of their data?

M. BRaUWERS. - Our results corroborate the interpretation of the absorption band observed by
Brandt and Brown as due to an electron bound in a Coulomb potential (size and kinetic energy in agreement with an hydrogen-like system). However, as our analysis is based on quantities integrated over the whole region occupied by the electron charge density, it is very little sensitive to the nature of the central imperfection and cannot distinguish between an $F$ center or a single-charged impurity center. 